\title{
A qualitative analysis of factors influencing infant and young children feeding perceptions and practices, of working mothers, in London Borough of Ealing
}

Anna Krivtsova MSc and Regina S. Keith PhD

University of Westminster, School of Life Sciences, College of Liberal Arts and Sciences

Corresponding author: Anna Krivtsova MSc GPHN

Email: krivcova.an@gmail.com; w1754637@my.westminster.ac.uk

Phone number: +37062482773; 077454533116

Address: Vilnius, Lithuania, Traku g. 16-23, LT-01132

Regina S. Keith RGN RM RPN MSc PhD SfHEA

Email: r.keith@westminster.ac.uk

Address:115 New Cavendish St, Fitzrovia, London W1W 6XH, UK

Conflict of interest disclosures: The authors have no conflicts of interest to report

Key words: EBF, peer support, formula-feeding, early cessation, complementary food, infant feeding, Ten Steps 


\section{Abstract}

Introduction: Optimum infant feeding practices, during the first 1000 days of life, are essential for children's health and development. The World Health Organization (WHO) recommends putting the infant to the breast within the first hour of life, and exclusively breastfeeding for six months. If every infant was exclusively breastfed 823,000 infant deaths could be avoided annually. Despite this fact only $41 \%$ of infants worldwide are exclusively breastfed. The Global Nutrition Target 5 seeks to increase this figure to $50 \%$ by 2025 . In the UK, although there is widespread knowledge on the benefits of breastfeeding, with $81 \%$ mothers initiating breastfeeding, only $24 \%$ are exclusively breastfeeding at 6 weeks. By six months only $1 \%$ of mothers are still exclusively breastfeeding. This is the lowest rate in Europe. This research aimed to explore the infant feeding practices and perceptions of a small group of working mothers, with children under the age of five, in the London Borough of Ealing.

Methodology: This study applied a qualitative methodology to gain a deeper understanding of factors influencing infant and young child feeding practices in a small group of working women. Two gatekeepers were used to recruit 14 participants through a mixture of convenience and snowball sampling. All mothers included were working and living in the Ealing Borough of London with children under five. Methods utilised for data collection included online interviews and open-ended surveys. Data were analysed using an inductive thematic approach, identifying four themes and eleven sub themes from the participants. Results: The study identified that mothers sought information on infant feeding from online sources, printed books, family and friends, and educational classes. However, most mothers expressed the need to have more information on different feeding methods and childbirth in general. Mothers highlighted that the main factors influencing their decision on how to feed their baby included the need to develop a strong connection with their baby, nutritional benefits for the infant and general knowledge about the benefits of breastfeeding. Most participants reported that they started breastfeeding at birth. Six mothers exclusively breastfed their baby until six months, followed by the introduction of complementary foods. Three of these mothers continued to breastfeed until nine months. Five mothers started formula feeding within two months due to personal challenges such as lack of support, perceived lack of milk supply and anatomical challenges such as tongue-tied infants. Mothers did not find work as a major barrier to breastfeeding.

Conclusions: Increased information and support on all aspects of infant feeding could help the UK achieve their 2025 target. The timing of complementary feeding and clear advice on where to seek nutrition support could be included in an English Infant Feeding Strategy, like the strategy implemented in Scotland. More discussion on the small size of an infant's stomach could reduce early breastfeeding cessation due to perceptions around lack of milk. 


\section{INTRODUCTION}

Optimum infant feeding practices are essential for children's health and development, especially in the first 1000 days of life (Michaelsen et al., 2000). Exclusive breastfeeding (EBF) for the first six months is one of the most effective ways to ensure child health and survival. According to (Black et al., 2013; WHO, 2020), if all infants from 0-6 months were exclusively breastfed, it could prevent up to 823000 child deaths, under five years old. every year. Despite this, only $44 \%$ of infants globally are exclusively breastfed until six months (UNICEF, 2019a). To encourage countries to increase support for nutrition, the United Nations Secretary General declared 2015-2025 the Decade of Nutrition, and 194 countries attending the 65th World Health Assembly in 2012, agreed to adopt several resolutions to promote maternal, infant, and young children's health. The Assembly agreed to establish six global nutrition targets, to be achieved by 2025; Target No.5 aims to increase EBF rates globally, among infants less than six months, up to at least $50 \%$ by the year 2025 (WHO, 2014; UN 2016). Continued low rates of EBF have raised public health concerns globally, resulting in a revision of the UNICEF Ten Step guidelines to successful breastfeeding, known as the Baby Friendly Hospitals Initiative (BFHI) (WHO, 2018). The revision promotes adapted factors ensuring all infants can have access to optimal nutrition intake, essential for growth and development (UNICEF, 2018). Some regions have surpassed the WHO EBF target, such as South Asia (57\%) and East and Southern Africa (56\%); these countries are encouraged to continue increasing towards higher rates. However, in the United Kingdom (UK), EBF rates are the lowest in Europe (UNICEF, 2019b). The last infant feeding survey in the UK was done in 2010 , which indicated that although $81 \%$ of mother's started to breastfeed, by six weeks only $23 \%$ were still exclusively breastfeeding, reducing to $17 \%$ at three months and $12 \%$ at four months (Mc Andrew et al. 2012). Only 1\% are still EBF at six months (UNICEF, 2021). However, according to UNICEF (2019b) EBF in the first six months was 43\% in Scotland for 2017.

Despite a clear national commitment to promoting breastfeeding in the UK, there are still many gaps in provision of breastfeeding support. Resulting in the breastfeeding rates remaining low, compared to other high-income countries (WBTI, 2016). For example, compared to Scandinavian countries, like Norway and Sweden where $80 \%$ and $78 \%$ of mothers respectively are still breastfeeding at six months (Häggkvist et al., 2010; Cato et al., 2020). Scotland has increased its breastfeeding rates since they implemented a National Infant Feeding Strategy, with 100\% of hospitals implementing the UNICEF BFHI Ten Steps and resources being allocated to support mothers (UNICEF UK, 2021). This includes immediate skin-to-skin contact after delivery, early initiation of breastfeeding within the first hour, correct positioning to avoid pain, and rooming-in to encourage maternal-infant bonding and the release of essential hormones (WHO, 2018).

Research in Tower Hamlets, in London, indicated that mothers were getting mixed messages regarding infant feeding from health workers and family members; mothers were also unsure who they should ask for support, as many local services had seen dramatic funding cuts in the last ten years (Keith et al., 2019). The provision of face-to-face support, from trained personnel, during the prenatal and postnatal period has been effective in helping mothers achieve their desired breastfeeding goals (Radzyminski and Callister, 2016; Keith et al., 2019). 


\section{Early breastfeeding cessation}

WHO advises that breastfeeding should be initiated within the first hour of life, excluding food or liquids until they are six months old (WHO, 2018). Despite an increase in breastfeeding initiation rates in the UK from $62 \%$ to $81 \%$ in $1990-2010$, breastfeeding rates during the first weeks of life have not changed, especially regarding the number of women still feeding at six months. McAndrew et al. (2012) explored the reasons for the low breastfeeding rates, discovering that early breastfeeding termination was unplanned: $80 \%$ of mothers said they would prefer to continue breastfeeding for the first six months, often citing difficulty in feeding and lack of support. According to Keith et al. (2019) the most common reasons for early breastfeeding termination reported by mothers were associated with the inability to latch on, pain, mixed messages, perceived inadequate milk supply, lack of support and going back to work. These findings supported the Infant Feeding Surveillance report (Infant Feeding Surveillance System, 2017), which revealed that early formula introduction was associated with concerns related to low milk supply, latching problems and medical complications. Despite all health staff, in Tower Hamlets, being trained in the UNICEF Ten Steps for successful breastfeeding, Keith et al. (2019) discovered many health workers gave incorrect messages, such as 'one bottle is ok', 'do not feed in public' and 'you do not have enough milk' to mothers. These mixed messages created confusion in mothers, resulting in early introduction of mixed feeding practices, which often led to early cessation of breastfeeding (Keith et al., 2019). Mothers and health workers are not always aware that a newborn stomach capacity allows it to hold only $20 \mathrm{ml}$ of fluid (Bergman, 2013). Even when health workers support breastfeeding, the cuts in staffing and health resources in the last ten years in the UK have resulted in many supporting services being overly stretched, including community infant feeding support groups (Keith et al., 2019); language and service integration and coordination were also significant barriers. Although the UK does support the ILO's (International Labour Organization) guidance of four months of paid maternity leave, extending this to six months paid leave in most government roles, many mothers still need to return to work within this essential period. With the growth of zero-hour contracts, more mothers are not able to take time off work, as many women need to travel to work, continuing to feed their baby, once they return to work, can be a challenge. Public Health England and UNICEF have developed a helpful resource to support working mothers in the UK, but it does not address all the practical barriers mothers face (Public Health England, 2015).

\section{Ealing Demographic Context}

According to the Joint Strategic Needs Assessment (2016), 86.5\% of mothers in Ealing Borough initiated breastfeeding, and $86.1 \%$ initiated breastfeeding in London, which is higher than the England average of 74.3\%. Although the data for Ealing are limited, the latest evidence (PHE, 2016) showed that 71\% of mothers still breastfeed at 6-8 weeks in Wales, which is higher than the UK average of about $47.9 \%$. In line with global and the national interventions to improve breastfeeding, Ealing Council has demonstrated commitment to support more mothers to optimally feed their infants. This includes supporting the implementation of BFHI through the local children's and health visiting centres such as Early Start Ealing. Early Start Ealing service aims to ensure that children are getting enough support and services to reach their full development and growth potential, by working with families to improve children's health, learning and social outcomes in children under five. The initiative works with public services, to ensure that parents receive clear and effective support with infant feeding, offering accurate and evidence-based information, ongoing support through health services and encouraging the UK government to protest these 
services. Health visitors are available seven days a week to give support for many children's issues including infant feeding (Ealing Council, 2021).

\section{Working mothers and infant feeding practices and perceptions}

Employed mothers, particularly those who work 30 hours per week and over, are less likely to initiate and sustain EBF due to lack of time, tiredness, or lack of support (Fein et al., 2008; Visness and Kennedy, 1997). A mother's employment is more likely to shape other infant feeding practices as well, and thus affect the formation of eating habits in later life due to maternal inability to dedicate enough time for child feeding and care (Popkin and Solon, 1976). Daniels et al. (2015) concluded that early introduction of complementary and foods (often perceived as a convenient feeding option; sometimes prematurely introduced foods are instead called "supplementary foods") due to mothers' employment might interfere with breastfeeding intensity and lead to early termination of breastfeeding.

Family and friends were identified to have an important role encouraging and supporting women to breastfeed, as well as providing information on infant feeding in a more informal environment (Chezem et al., 1999; Grossman,1990; Marchand \& Morrow, 1994; Mahoney and James, 2000). Books and media sources, knowledge of breastfeeding (Shelton, 1994; Gage, et al., 2012), and intention to breastfeed (Blyth, et al., 2004; DiGirolama, et al., 2005; Forster, et al., 2006) have all been identified as significant determinants of infant feeding choices.

Similarly, Radziminsky and Callister (2016) explored maternal perceptions and decision making of infant feeding finding that understanding of bonding with the infant, nutritional benefits and general knowledge contributed to the maternal decision to breastfeed. Cox et al. (2015) also revealed that personal convenience, health, and monetary factors increase the likelihood of mothers' choice to breastfeed, rather than introducing formula. Some observational studies (Moore et al., 2007; McFadden and Toole, 2006; Dykes et al., 2003) have examined the primary sources of information that women tend to rely on when deciding what and how infants need to be fed, suggesting that mothers may likely to rely on books, leaflets, and other written sources as the primary source of information about feeding practices. As previous research identified, mothers receive information about IYCF both breast and formula feeding attending antenatal classes and peer support groups (Giugliani et al., 1994; Matthews et al., 1998). Prenatal classes and peer groups improve women's knowledge and competence with childbirth and feeding practices (Spinelli et al., 2003) and are associated with increased breastfeeding duration (Ingram \& Johnson, 2004; Dennis et al., 2002; Lawson \& Callaghan, 1991; Scott et al., 2001).

A comparative study conducted in the UK has identified a lack of sufficient knowledge and professional support from healthcare workers about infant feeding, determined by a lack of time and resources to provide quality support (Brown et al., 2011). Keith et al. (2019) also found that mothers trusted health workers for infant feeding information; however most preferred the internet sources, family, and friends' advice because of ease of access. This study also revealed that mothers faced inconsistent advice, lack of support postnatally, and mixed messaging regarding infant feeding practices which caused confusion. When health workers gave mixed messages, then family's advice would be listened to and trusted, such as when to stop breastfeeding and add solid foods.

Earlier UK research on infant feeding showed the most common complementary foods introduced included homemade fruit and vegetable purees, baby rice, or cereal (Lennox et al., 
2013). Similarly, Grzywacz et al. (2010) exploring infant feeding patterns at eight months in the US, found that full-time working mothers were more likely to be feeding their infant at that age with fruits $(92,0 \%)$, vegetables $(93,4 \%)$, infant cereals $(92,4 \%)$, infant formula $(86,4 \%)$ and dairy products $(50,8 \%)$ than non-working mothers. This study's estimates also identified a high proportion of mothers who fed their infant with combination dinners, including pre-packaged food sources and junk foods given as a quick snack, whereas only $23,7 \%$ these mothers were still breastfeeding at eight months.

Over the last few decades, an alternative feeding approach called baby-led-weaning (BLW) has become more popular among mothers. This approach is allowing infants to handle food and feed themselves, instead of being spoon-fed by parents. The guidelines of the introduction of finger foods differ around the globe. WHO and UNICEF (2003) advice is to start introducing finger foods from eight months alongside breast milk. The UK Department of Health $(\mathrm{DoH})$ recommends the introduction of finger foods along with complementary foods (Brown et al., 2017). WHO and NHS both recommend introducing solid foods at six months of age having achieved developmental readiness, as it may significantly increase the risk of gastrointestinal and respiratory disorders, ear infections and obesity (Wilson et al., 1998; Armentia et al., 2001; Kramer \& Kakuma 2004; Wright et al., 2004; Huh et al., 2011).

\section{Aims and objectives}

This study aimed to explore the IYCF practices and perceptions of working mothers within the London Borough of Ealing.

The objectives of the study were to:

- Identify the factors influencing the choice of IYCF practices of participants

- Determine infant and young children feeding practices of participants

- Establish the barriers and reasons for early breastfeeding cessation

\section{METHODS \\ Study Design}

This study was conducted using a qualitative approach, which was identified to be an appropriate and effective way to conduct the present exploratory study. Understanding complex factors around infant feeding requires more in depth understanding on the factors influencing these mothers. The qualitative approach is an effective way to provide the research with deep, rich, and contextual data based on natural human experiences, opinions, and feelings Maxwell (2012). This approach is advantageous as it provides in-depth, complex, and illustrative information about a phenomenon which cannot be quantified. The qualitative approach also requires a smaller sample size to capture and understand the essential aspects of the studied phenomenon with depth (Vasileiou et al., 2018); during a global pandemic this was a much more realistic approach. However, when adopting a qualitative method, precaution must be taken, as the approach implies several limitations associated with the time-consuming process and a high degree of potential response and researcher bias (Rahman, 2017).

\section{Pilot study}

To support enhanced validity and rigour of the research, Nunnaly (1978) recommends getting subject experts to assess the questions. This was carried out through an academic midwife, with forty years' experience. The CASP (2018) qualitative checklist was utilised to support enhanced credibility, reliability, and validity of the research process. Bush (2007) and Burns and Grove (1993) consider that validity can be established by considering the degree to which 
the adopted instrument has covered the content that it was supposed to measure. For the pilot study, five working mothers, with a child under five years old were recruited. The online interviews were conducted via Skype, and responses were recorded for further analysis using an audio recorder. Participants reported that some questions lacked clarity, the topic guide was changed in line with feedback and retested.

\section{Sampling technique and sample size}

The research included 14 working mothers in Ealing borough of London, reached through convenience and snowball sampling, using two gatekeepers from a local church community group working with mothers with children under five and a local National Childbirth Trust (NCT) group. Braun and Clarke (2013) suggest that data saturation in qualitative study can occur after around twelve respondents have been interviewed. However, in this research saturation occurred after 14 participants. As qualitative research is a moment in time, a window on the world, to gain a greater depth of understanding of participants views, even small samples can yield valuable information.

\section{Data collection methods}

This study used a mixture of two data collection methods: semi-structured interviews over the phone, using Skype, and online questionnaires that were emailed or sent via phone text to the study participants. Data were collected using semi-structured interviews $(n=8)$ via phone and questionnaires via email $(n=6)$. The interviews lasted an average of 20 minutes and were recorded using a standard mobile phone audio-recorder. Semi-structured interviews were used because they allow sufficient freedom and flexibility of expression, data comparability and thus contributed to exploration of the question with a greater depth (Queirós et al., 2017). The data collection method over the telephone interviews or online questionnaires were chosen due to circumstances associated with Covid-19 and UK mandatory isolation (lockdown) measures. The telephone interview technique involved a series of open-ended questions. Participants were given the ability to choose the most convenient interviewing option upon their preference and availability, resulting in an increased interest in supporting the study and willingness to participate.

\section{Analysis}

The data analysis involved the transcription of the recorded data and data coding using an inductive thematic analysis approach to identify and analyse the main concepts and key issues reported by participants during the interview. The thematic analysis method was used to structure, organise, and interpret data, as it enables the researcher to summarise the key features of the main data set and produce trustworthy, rich, and insightful findings (Braun and Clarke, 2013; King, 2004). Although the method provides certain flexibility for data analysis, this may lead to inconsistencies and lack of coherence during the coding process (Holloway \& Todres, 2003). Consistency and cohesion can be achieved by constructing detailed and robust data analysis plans, providing a detailed description and interpretation of all data aspects (Braun and Clarke, 2013). During the data analysis, four major themes and eleven codes or subthemes were identified.

\section{Ethics}

Ethical approval was received from the University of Westminster, prior to data collection (ETH1920-1534). This study was conducted according to the University of Westminster Ethical guidelines. All study participants were emailed consent and information forms about 
the study purposes before the data collection to assure that participants agree to participate in the study. Participants were allowed to withdraw from the study at any time, and all participation was voluntary. To assure participants confidentiality, no names and personal information were included in the data. The collected data were stored in a GDPR compliant password locked file. The study excluded mothers who were less than six weeks postpartum and/or with any vulnerability such as postnatal depression or any other type of mental illnesses after pregnancy.

\section{RESULTS}

Four major themes and subthemes were extracted from the data collected through an inductive approach. These can be seen in Table 1.

Table 1. Themes and sub-themes for the analysis

\begin{tabular}{|l|l|}
\hline Themes & Sub-themes \\
\hline Determinants of feeding choices & $\begin{array}{l}\text { Family experience } \\
\text { Nutritional Benefits for the Infant } \\
\text { Convenience and cost }\end{array}$ \\
\hline Barriers to breastfeeding & $\begin{array}{l}\text { Pain and discomfort } \\
\text { Anatomical problems } \\
\text { Need for better support and advice } \\
\text { Mixed messages }\end{array}$ \\
\hline Infant and Young Child Feeding & $\begin{array}{l}\text { Infant feeding patterns } \\
\text { Determinants of solid foods introduction }\end{array}$ \\
\hline Communication & $\begin{array}{l}\text { Sources of information } \\
\text { Insufficient information }\end{array}$ \\
\hline
\end{tabular}

\section{Determinants of feeding choices}

\section{Family experience}

This theme presents the findings on participants' thoughts and feelings about the factors that influenced their infant feeding choice. Overall, most mothers felt that their parents strongly influenced their infant feeding decision. Most mothers reported that they relied on their mother's feeding experience and knowledge, and some reported that they have listened to their friends' advice.

P12: "My mum breastfed me for the first three months of my life, and I've read that it was much more beneficial to the mother and baby."

P5: "All women in my family have breastfed, so I thought it is what my baby needs."

\section{Nutritional Benefits for the Infant}

All mothers reported that knowledge about the nutritional and health benefits of breast milk encouraged them to breastfeed.

P6: "I chose to breastfeed my baby because I've read about its protective properties, and it's best for the baby's health." 
Five mothers reported that the feeling of bonding with a baby was an important factor which determined their infant feeding choice.

P1: "I decided to breastfeed for the second time as I like the bonding between mother and child, and I wanted to provide the all-important antibodies from birth."

\section{Convenience and cost}

Several mothers chose to breastfeed because it was accessible and cost less than formula feeding, at the same time considering benefits for mothers' health.

P10: "Heard and read lots about health benefits for women and also a monetary factor, so I thought that it would be good for my baby and also cheaper."

Some participants mentioned that they preferred breastfeeding over formula feeding as it offered personal convenience

P13: "Well... I think mostly convenience because I was busy with my first child who had just started school..."

\section{Barriers to breastfeeding}

This theme presents the findings of the issues and challenges associated with breastfeeding initiation and early breastfeeding termination before six months. Although several mothers have reported that they have successfully exclusively breastfed their baby until six months, most women reported that they did not meet their desired breastfeeding duration due to several factors.

\section{Pain and discomfort}

Nearly all mothers have reported that they have experienced problems with lactation, citing breast pain, cracked and bleeding nipples and insufficient milk supply. This, as a result, contributed to an early introduction of bottle-feeding, as it seemed the best option in order not to starve their baby.

P12: "My nipples cracked, bled and scabbed over by day 2, and my husband started to bottle feed her as I became too upset to hold her, and my milk supply was very low."

P11: “..my milk never really came up, and my supply was always low. Her appetite increased, and that made it very difficult to remove the formula from her diet completely."

One mother reported facing the challenge to breastfeed in a public place: P2. "... sometimes I felt judged, watched, and not understood, so I had to adapt."

\section{Anatomical problems}

The tongue-tied babies were identified as a significant barrier to latch on properly, which made lactation difficult and painful. Three mothers have referred their struggles to breastfeed as their baby was unable to latch on deeply, causing discomfort, bleeding, and soreness of nipples. 
P1: "I struggled to breastfeed for the second time as the baby was tongue-tied, so we found a private lactation specialist to help me with that."

P11: "It was very painful, the baby was tongue-tied, so she wasn't latching very good, my milk never really came up, and my supply was always low."

\section{Need for better support and advice}

Participants' responses regarding professional support and advice were mixed. However, nearly all participants noted that they would like to get more accurate and comprehensive information. Most mothers admitted that they would like to get more practical advice and guidance on positioning and latching on, particularly with tongue-tied babies. Several mothers expressed their willingness to know more about other possible alternative feeding methods such as Supplemental Nursing System, as it would have helped to make more effort to breastfeed. More mothers reported they would like to get more information on recovery and complications after $\mathrm{C}$-section and pain relief during delivery.

P13: "I wish I knew that it was fine and normal how-to co-sleep with my baby from birth while it fed; my midwife never told me about it so I didn't."

P12: "A midwife sold me a breast pump but didn't get round to telling me how to use it, so that exacerbated the problem."

\section{Mixed messages}

Participants noted that the information on infant feeding differed between sources, which led to confusion.

P14: "I actually found the NHS antenatal class on infant feeding a bit confusing as the information differed from the information provided at my NCT class."

P1: "...I felt so unsupported. Health visitors were continually telling me to formula feed as he was not gaining enough weight, so we decided to find a lactation specialist who was fantastic, and she reassured me to continue to breastfeed only."

\section{Infant and Young Child Feeding}

This theme presents the results gathered on infant and young child feeding practices of working mothers.

\section{Infant feeding practices}

Most participants reported that they started breastfeeding at birth. Six mothers said that they exclusively breastfed their baby until 5-6 months, followed by an introduction of complementary foods, as recommended. Three mothers continued to breastfeed until between nine and twelve months. Five mothers noted that formula feeding was introduced earlier, citing inadequate milk supply, pain, lack of sleep, tiredness and severe tongue-tie as contributing factors to start bottle feeding two months.

P13: "I found breastfeeding painful and awkward...I began to express milk using a handheld pump, but after 2 or 3 weeks, my milk reduced, and I exclusively bottlefed."

P7: "I started trying to breastfeed when my child was born, and I stopped when he was about 2.5 months old and started to give him formula. I mainly found breastfeeding difficult because of the rashes and lack of sleep that resulted from it and getting up every time to feed my baby was quite tiring on top of all of it." 
P7: "... I needed help from my husband to feed my baby. I was exhausted and found it extremely hard to move and I wasn't producing enough milk."

\section{Introduction of complementary foods}

Most participants reported that the first solid foods were introduced between 5 and 6 months of age. A few reported the earlier introduction of solids between four and five months. The most common solid foods introduced were banana and raw avocado, mothers were citing its soft texture, taste, and nutritional benefits. Others reported that they introduced steamed or pureed vegetables and fruits, such as zucchini, potatoes, butternut squash, broccoli, and carrots, citing its low likelihood to cause stomach irritation.

Two mothers reported that they had adopted the baby-led weaning (BLW) method, as it was previously practiced in their family and recommended as a better way to introduce solid foods. As one mother reported:

P12: "I decided to do BLW with both children as my sister-in-law used the same method and she recommended it to me, so we first started with vegetable sticks". P9: "Solid foods were introduced at six months, it was boiled carrot, courgette, broccoli, I started with veggies as I knew it is what baby needs first, it won't cause an allergic reaction, help her digestion."

P3: "I introduced solids at four months, as she started showing interest in food."

\section{Communication}

A fourth major theme identified was mothers' thoughts regarding the main sources of information they relied on and advice on infant and child feeding.

\section{Sources of information}

Most mothers said that they mostly relied on the information provided on the NHS website, as it made them feel confident and secure, believing that all its information was studied and scientifically proven. Five mothers reported that they had attended antenatal peer and support groups on breastfeeding and postnatal groups on weaning practices. They found these groups helpful, informative, and appropriate, positively contributing to their IYCF practices and general knowledge. Most mothers also reported that they relied on printed books written by paediatricians, and some of them relied on their mothers' and friends' feeding experience.

\section{Insufficient information}

Several participants felt that information on breastfeeding attachment and positioning techniques was superficial or lacking, particularly for mothers with tongue-tied babies. Mothers reported that they would like to have more detailed and accurate information about comfortable positioning and latching, so it can relieve breast pain, discomfort, and help them to increase breastfeeding duration.

P11:' '...I would say I would like to get more information about tongue-tie babies latching and how to discover this before it is too late."

P3: 'More information on breastfeeding maybe, so mothers can be prepared and know more about positioning and latching, especially for those who have inverted nipples."' 


\section{DISCUSSION}

\section{Determinants of feeding choices}

The present study's findings echo results from other research such as Keith et al. (2019) which highlight that maternal decision-making regarding IYCF is multi-factorial. Family members and friends often give advice on infant feeding based on their experience. This advice is especially relied upon when health workers give unclear or mixed messages. Breastfeeding mothers cited their mothers' experience and knowledge as a significant factor in why they chose to breastfeed over formula feeding. These findings are similar to research carried out by Mahoney and James (2000), who found that family and friends often influence maternal decision making related to infant feeding.

The research also supports many other research studies, including (Keith et al., 2019), demonstrating, that mothers were aware of the importance of exclusive breastfeeding. Mothers who wanted to ensure they bonded with the infants and were keen to promote the nutritional benefits for the infant breastfed for longer. It would be interesting to see if this would be the case in a different group of women in a non-pandemic context. However, these findings are echoed in research by Radziminsky and Callister (2016).

The mothers also cited a clear perception of breastfeeding as an inexpensive and convenient feeding method as a contributory factor determining the infant feeding choice. This was in line with the previous research findings by Cox et al. (2015), who found that those mothers who believed that breastfeeding offers convenience and is cost-effective were more likely to choose breastfeeding as the main feeding option and less likely to introduce formula. Interestingly, the study found that those mothers who believed that breastfeeding could improve bonding between mother and infant continued breastfeeding longer, until 9-12 months.

\section{Barriers to breastfeeding}

The current study also identified clear challenges associated with breastfeeding initiation and the reasons for early breastfeeding cessation before six months. The study found that although mothers expressed their desire to breastfeed for longer. Barriers were associated with concerns regarding insufficient and superficial information that mothers were provided. Lack of professional support, pain and discomfort, anatomical complications and mother's perceptions of inadequate milk supply led to early termination and bottle introduction. These findings also reflect McAndrew et al.'s finding (2012) that common reasons for early breastfeeding cessation are generally associated with the inability to latch, breast pain, and painful nipples. Edmunds et al. (2011) also reviewed factors associated with early termination, showing that mothers with tongue-tied babies are more likely to experience pain and have difficulties with latching. However, none of the mothers related early cessation of breastfeeding and problems associated with BF with their employment. This could be due to the group of women included in the study, as most were not in zero-hour informal employment. Mothers reported the lack of information and support about positioning and attachment and infants with anatomical problems. This demonstrates the need to provide new and expectant mothers with more detailed and precise information and signpost where they can seek further help. It is essential to provide mothers with continued professional guidance and assistance to help mothers and babies reach an optimal latch, comfort positioning, and help mothers meet their desired breastfeeding duration. 
Barriers to mothers continuing breastfeeding included the lack of timely support and the mixed messages regarding adding bottle feeds, despite all staff being trained in the Ten Steps. Another significant barrier raised was maternal misperceptions of not having enough milk to meet baby needs, which increased concerns about infant weight. These fears were not always addressed by health workers, resulting in the addition of formula feeds, which sometimes leads to early cessation of breastfeeding. According to recent research in the London Borough of Tower Hamlets, Keith et al. (2019) found similar problems of unclear communication, perceived lack of milk, and pain as significant reasons for early cessation, in line with earlier research (Li et al., 2008; Neifert, 2004). Mothers and health workers could benefit from more support on the amount of milk young infants need, given that their stomachs only hold $20 \mathrm{ml}$ at birth.

\section{IYCF Practices}

The current study also found that mothers seek information on infant feeding from various sources. Mothers mostly relied on the NHS website, citing their confidence, and feeling secure as they believed that all information presented is evidence-based and well-studied. However, it should be noted that the website does not explain the differences between breastfeeding and formula feeding for infants, which may affect maternal perception and views about breastfeeding and impact their feeding behaviour.

Mothers also seek out information from books written by paediatricians and online articles supported in a study by (Moore et al.,2007; McFadden and Toole, 2006; Dykes et al.,2003). As previous research established that mothers often receive information on IYCF practices, both breast and formula feeding, there were mixed experiences with support from various sources. Some women felt that they had been given good access to peer counselling. However, the majority reported the need to get more detailed and accurate information on complementary foods, additional guidance on comfortable positioning and latching, particularly with tongue-tied babies, pain relief during delivery, complications after Csection, and alternative feeding practices.

As study findings also highlighted the need for more in-depth information about complementary foods, which demonstrates the importance of providing mothers with detailed information on breastfeeding and weaning in line with the WHO and UNICEF (2003) recommendations. Furthermore, challenges associated with breastfeeding due to lack of assistance and support from health professionals should be given more resources and attention to ensure mothers receive consistent support and clear advice at hospitals and homes. This also could be done by strengthening antenatal and postnatal counselling, providing adequate lactation support assistance, incorporating benefits about breastfeeding and related challenges during breastfeeding.

\section{Limitations}

There were several limitations in carrying out the research, such as the impact of COVID 19 on face-to-face interviews. Online interviews are not always as effective for in-depth qualitative analysis for many reasons such as time, trust, and rapport, which can be developed face to face. On the other hand, telephone interviews allowed communication without visual access, which increased participants' willingness to share their personal experiences and feel more confident during the interview (Fontana \& Frey, 2005). The lockdown restricted normal methods of gathering participants for research. Hence using snowball and convenience sampling from a church group and a local NCT group could result in similar perceptions and practices. However, as the borough was trying to promote effective infant and young child 
feeding practices and increase EBF rates, the voice of working women, even in a limited sample, was considered an important consideration in this borough, as many mothers need to work. Some limitations were identified when using online interviews, such as poor connectivity for some participants, but these then used questionnaires to answer. As many mothers could not work during lockdown, it would be good to follow this study up following the return to normal working patterns in the borough.

\section{CONCLUSIONS}

The research findings showed the importance of prioritising breastfeeding and ensuring its promotion and support by strengthening antenatal and postnatal counselling. This includes providing clear advice and accurate information on infant feeding to ensure mothers meet their desired breastfeeding goals and provide optimal nutrition for their child. The study identified that mothers' decision to breastfeed, formula feed or combination feed an infant influenced by a variety of factors, including information obtained and advice offered from family and friends, peer groups and antenatal classes and through reading materials. The study also found that those who believed that breastfeeding improves maternal-infant bonding were more likely to have continuous breastfeeding until nine and twelve months.

Ensuring mothers receive consistent support and clear advice from trained and skilled personnel at hospitals and homes is an essential investment for local government and the NHS. This includes facilitating breastfeeding, providing adequate lactation support assistance with positioning, and latching, promoting skin-to-skin contact and rooming-in to encourage activation of hormone release and maternal-infant bonding. To this matter, informing mothers about an infant's stomach's small size would also help prevent mothers' misperceptions about the amount of fluid the baby needs.

\section{Acknowledgements}

The first author would like to thank everyone who guided, supported, and motivated her through this project journey. She also wishes to express her gratitude to her lecturer and project supervisor who was responsive, helpful, and supportive through her academic year and during her final project. 


\section{REFERENCES}

Armentia, A., Bañuelos, C., Arranz, M. L., Del Villar, V., Martín-Santos, J.-M., Gil, F. J. M., Vega, J. M., Callejo, A., Paredes. C., 2001. Early introduction of cereals into children's diets as a risk-factor for grass pollen asthma. Clinical \& Experimental Allergy, 31(8):1250-1255. https://doi.org/10.1046/j.1365-2222.2001.01142.x

Bergman N, 2013. Neonatal stomach volume and physiology suggest feeding at 1-h intervals. Acta Paediatrica, 102:773-777. https://doi.org/10.1111/apa.12291

Black RE, Victora CG, Walker SP, et al. 2013. Maternal and child undernutrition and overweight in low-income and middle-income countries. The Lancet, 382(9890):427-451. https://doi.org/10.1016/S0140-6736(13)60937-X

Blyth, R.J., Creedy, D.K., Dennis, C.L., Moyle, W., Pratt, J., De Vries, S.M. and Healy, G.N., 2004. Breastfeeding duration in an Australian population: the influence of modifiable antenatal factors. Journal of Human Lactation, 20(1):30-38.

Braun, V. and Clarke, V., 2013. Successful qualitative research: A practical guide for beginners. Sage.

Brown A, Raynor P, and Lee M, 2011. Healthcare professionals' and mothers' perceptions of factors that influence decisions to breastfeed or formula feed infants: a comparative study. Journal of Advanced Nursing, 67(9):1993-2003. https://doi.org/10.1111/j.13652648.2011.05647.x

Brown A, Jones SW, and Rowan H, 2017. Baby-led weaning: the evidence to date. Current Nutrition Reports, 6(2):148-156.

Burns N, and Groves K, 1997. Practice of Nursing Research. Philadelphia, PA: WB Saunders Company.

Bush, T., 2007. Authenticity in research-reliability, validity, and triangulation. Research methods in educational leadership and management, 91.

CASP (2018) CASP: Qualitative checklist. https://casp-uk.b-cdn.net/wpcontent/uploads/2018/03/CASP-Qualitative-Checklist-2018 fillable_form.pdf

Cato K, Sylvén SM, Henriksson HW, and Rubertsson C, 2020. Breastfeeding as a balancing act-pregnant Swedish women's voices on breastfeeding. International Breastfeeding Journal, 15(1):1-9.

Chezem, J. and Friesen, C., 1999. Attendance at breast-feeding support meetings:

Relationship to demographic characteristics and duration of lactation in women planning postpartum employment. Journal of the Academy of Nutrition and Dietetics, 99(1):83.

Cox, K.N., Giglia, R.C. and Binns, C.W., 2015. The influence of infant feeding attitudes on breastfeeding duration: evidence from a cohort study in rural Western Australia. International Breastfeeding Journal, 10(1):1-9. 
Daniels L, Mallan KM, Fildes A, Wilson J, 2015. The timing of solid introduction in an 'obesogenic' environment: a narrative review of the evidence and methodological issues. Aust NZ J Public Health, 39:366-373. https://doi.org/10.1111/1753-6405.12376

Dennis, C.L., 2002. Breastfeeding initiation and duration: A 1990-2000 literature review. Journal of Obstetric, Gynecologic, \& Neonatal Nursing, 31(1):12-32

DiGirolamo, A., Thompson, N., Martorell, R., Fein, S. and Grummer-Strawn, L., 2005. Intention or experience? Predictors of continued breastfeeding. Health Education \& Behavior, 32(2):208-226.

Dykes, F., Moran, V.H., Burt, S. and Edwards, J., 2003. Adolescent mothers and breastfeeding: experiences and support needs - an exploratory study. Journal of Human Lactation, 19(4):391-401.

Ealing Council, 2021. Early Start Ealing 0-19: Support for families with children. https://www.ealingfamiliesdirectory.org.uk/kb5/ealing/directory/advice.page?id=vQgsDhte8 $\underline{\mathrm{GA}}$

Edmunds J, Miles S, and Fulbrook P, 2011. Tongue-tie and breastfeeding: a review of literature. Breastfeeding Review, 19(1):19-26.

Fein SB, Mandel B, Roe BE, 2008. Success of strategies for combing employment and breastfeeding. Pediatrics, 122:S56-S62. https://doi.org/10.1542/peds.2008-1315g

Fontana A, \& Frey J, 2005. The Interview: From Neutral Stance to Political Involvement. In The Sage Handbook of Qualitative Research (3rd ed.). Thousand Oaks, CA: Sage.

Forster, D.A., McLachlan, H.L. and Lumley, J., 2006. Factors associated with breastfeeding at six months postpartum in a group of Australian women. International Breastfeeding Journal, 1(1):1-12.

Gage, H., Williams, P., Von Rosen-Von Hoewel, J., Laitinen, K., Jakobik, V., MartinBautista, E., Schmid, M., Egan, B., Morgan, J., Decsi, T. and Campoy, C., 2012. Influences on infant feeding decisions of first-time mothers in five European countries. European Journal of Clinical Nutrition, 66(8):914-919.

Giugliani, E.R., Caiaffa, W.T., Vogelhut, J., Witter, F.R. and Perman, J.A., 1994. Effect of breastfeeding support from different sources on mothers' decisions to breastfeed. Journal of Human Lactation, 10(3):157-161.

Grossman, L.K., Harter, C., Sachs, L. and Kay, A., 1990. The effect of postpartum lactation counseling on the duration of breast-feeding in low-income women. American Journal of Diseases of Children, 144(4):471-474.

Grzywacz JG, Tucker J, Clinch CR, and Arcury A, 2010. Individual and job-related variation in infant feeding practices among working mothers. American Journal of Health Behavior, 34(2):186-196. https://doi.org/10.5993/AJHB.34.2.6 
Häggkvist AP, Brantsæter AL, Grjibovski AM, Helsing E, Meltzer HM, and Haugen M, 2010. Prevalence of breast-feeding in the Norwegian Mother and Child Cohort Study and health service-related correlates of cessation of full breast-feeding. Public Health Nutrition, 13(12):2076-2086.

Hitt R, Zhuang J, and Anderson J, 2018. Media presentation of breastfeeding beliefs in newspapers. Health Communication, 33(10):1293-1301. https://doi.org/10.1080/10410236.2017.1351275

Holloway, I. and Todres, L., 2003. The status of method: flexibility, consistency and coherence. Qualitative research, 3(3):345-357.

Infant Feeding Surveillance System, 2017. Formula Introduction and Breastfeeding. https://www.durham.ca/en/health-and-

wellness/resources/Documents/HealthInformationServices/HealthStatisticsReports/FormulaIntroduction-and-Breastfeeding.pdf

Ingram, J. and Johnson, D., 2004. A feasibility study of an intervention to enhance family support for breast feeding in a deprived area in Bristol, UK. Midwifery, 20(4):367-379.

Huh SY, Rifas-Shiman SL, Taveras EM, Oken E, and Gillman MW, 2011. Timing of solid food introduction and risk of obesity in preschool-aged children. Pediatrics, 127(3):e544e551. https://doi.org/10.1542/peds.2010-0740

Joint Strategic Needs Assessment, 2016. Children and Young People. JSNA [online] Ealing Council. http://Children_and_Young_People_EalingJSNA_2016.pdf

Keith RS, Mba EU, Li X, Wright D, 2019. Exploring infant \& young child feeding (IYCF) practices \& perceptions in the London Borough of Tower Hamlets. World Nutrition, 10(1):18-37. https://dx.doi.org/10.26596/wn.201910118-37

King, N., 2004. 21 Using Templates in the Thematic Analysis of Text, Essential guide to qualitative methods in organizational research, p.256.

Kramer MS, and Kakuma R, 2004. The Optimal Duration of EBF. In Protecting Infants Through Human Milk (pp. 63-77). Springer, Boston, MA.

Kramer MS, and Kakuma R, 2012. Optimal duration of EBF. Cochrane Database of Systematic Reviews, Nr. 8. https://doi.org/10.1002/14651858.CD003517.pub2

Lawson, J.S. and Callaghan, A., 1991. Recreating the village: the development of groups to improve social relationships among mothers of new born infants in Australia. Australian Journal of Public Health, 15(1):64-66

Lennox A, Sommerville J, Ong K, Henderson H, and Allen R, 2013. Diet and Nutrition Survey of Infants and Young Children, 2011. A survey carried out on behalf of the Department of Health and Food Standards Agency. 
Li R, Fein SB, Chen J and Grummer-Strawn LM, 2008. Why mothers stop breastfeeding: mothers' self-reported reasons for stopping during the first year. Pediatrics, 122(Supplement 2):S69-S76.

Mahoney, M.C. and James, D.M., 2000. Predictors of anticipated breastfeeding in an urban, low-income setting. Journal of Family Practice, 49(6):529-529.

Marchand, L. and Morrow, M.H., 1994. Infant feeding practices: understanding the decisionmaking process. Family Medicine, 26(5):319-324.

Matthews, K., Webber, K., McKim, E., Banoub-Baddour, S. and Laryea, M., 1998. Maternal infant-feeding decisions: reasons and influences. Canadian Journal of Nursing Research, 30(2):177-198. https://cjnr.archive.mcgill.ca/article/view/1449

Maxwell, J.A., 2012. Qualitative research design: An interactive approach (Vol. 41). Sage publications.

McAndrew F, Thompson J, Fellows L, Large A, Speed M, and Renfrew MJ, 2012. Infant Feeding Survey 2010. Health and Social Care Information Centre. https://sp.ukdataservice.ac.uk/doc/7281/mrdoc/pdf $/ 7281$ ifs-uk-2010_report.pdf

McFadden, A. and Toole, G., 2006. Exploring women's views of breastfeeding: a focus group study within an area with high levels of socio-economic deprivation. Maternal \& Child Nutrition, 2(3):156-168.

Michaelsen KF, 2000. Feeding and nutrition of infants and young children: guidelines for the who European region, with emphasis on the former Soviet countries (No. 87). WHO Regional Office Europe.

Moore, E.R. and Anderson, G.C., 2007. Randomized controlled trial of very early motherinfant skin-to-skin contact and breastfeeding status. Journal of Midwifery \& Women's Health, 52(2):116-125

Neifert MR, 2004. Breastmilk transfer: positioning, latch-on, and screening for problems in milk transfer. Clinical Obstetrics and Gynaecology, 47(3):656-675.

Nunnally JC, 1978. Psychometric Theory 2nd ed. McGraw Hill Book Company. Office of the Surgeon General US, 2011. The Surgeon General's Call to Action to Support Breastfeeding.

Popkin BM, Solon FS, 1976. Income, time, the working mothers and child nutrition. J Trop Pediatr Envt Child Health, 22:156-166.

Public Health England, (2015). Breastfeeding after returning to work or study: information for employees and employers, students and course providers PHE with UNICEF UK. https://www.unicef.org.uk/babyfriendly/wpcontent/uploads/sites/2/2008/04/breastfeedingandwork.pdf

Public Health England, (2016). Children and Young People's Health Benchmarking Tool. 
Queirós A, Faria D, and Almeida F, 2017. Strengths and limitations of qualitative and quantitative research methods. European Journal of Education Studies, 3(9):369-386. DOI: $10.5281 /$ zenodo.887089.

https://www.researchgate.net/publication/319852576_Strengths_and_Limitations_of_Qualitat ive and Quantitative_Research_Methods

Radzyminsky S, and Callister LC, 2016. Mother's beliefs, attitudes, and decision making related to infant feeding choices. The Journal of Perinatal Education, 25(1):18. DOI: $10.1891 / 1058-1243.25 .1 .18$

Rahman, M.S., 2017. The advantages and disadvantages of using qualitative and quantitative approaches and methods in language "testing and assessment" research: a literature review. Journal of Education and Learning, 6(1):102-112. doi:10.5539/jel.v6n1p102

Scott, J.A., Landers, M.C.G., Hughes, R.M. and Binns, C.W., 2001. Factors associated with breastfeeding at discharge and duration of breastfeeding. Journal of Paediatrics and Child Health, 37(3):254-261.

Shelton, K., 1994. Empowering women to breastfeed successfully. Breastfeeding Review, 11(10):455-458.

Spinelli A, Baglio G, Donati S, Grandolfo ME, and Osborn J, 2003. Do antenatal classes benefit the mother and her baby? The Journal of Maternal-Fetal \& Neonatal Medicine, 13(2):94-101. https://doi.org/10.1080/jmf.13.2.94.101

UNICEF, 2003. The State of the World's Children 2004, Girls, education and development. UNICEF.

UNICEF, and UNAIDS, 2003. Global Strategy for Infant and Young Child Feeding. WHO. https://www.who.int/nutrition/publications/infantfeeding/9241562218/en/

UNICEF, 2018. Levels and trends in child malnutrition. eSocialSciences.

UNICEF, 2019a. Infant and Young Child Feeding.

https://data.unicef.org/topic/nutrition/infant-and-young-child-feeding/

UNICEF, 2019b. Breastfeeding: A Public Health Issue.

https://www.unicef.org.uk/babyfriendly/about/breastfeeding-in-the-uk/

UNICEF UK, 2021. Breastfeeding in the UK.

https://www.unicef.org.uk/babyfriendly/about/breastfeeding-in-the-uk/

United Nations,2016. Decade of Nutrition Resolution document A/70/L.42.

https://www.un.org/press/en/2016/gal1770.doc.htm

Vasileiou K, Barnett J, Thorpe S, and Young T, 2018. Characterising and justifying sample size sufficiency in interview-based studies: systematic analysis of qualitative health research over a 15-year period. BMC Medical Research Methodology, 18(1):148. doi:

10.1186/s12874-018-0594-7. 
Visness CM, and Kennedy KI, 1997. Maternal employment and breast-feeding: findings from the 1988 National Maternal and Infant Health Survey. American Journal of Public Health, 87(6):945-950. https://doi.org/10.2105/AJPH.87.6.945

WHO and UNICEF (2003) Complementary feeding: report of the global consultation, and summary of guiding principles for complementary feeding of the breastfed child.

WHO, 2014 a. Global Nutrition Targets 2025: Breastfeeding Policy Brief (WHO/NMH/NHD14. 7). Geneva: WHO. https://www.who.int/nutrition/publications/globaltargets2025 policybrief breastfeeding/en/

WHO, 2014 b. Global Nutrition Targets 2025: Policy Brief Series (No. WHO/NMH/NHD/14.2). WHO. https://www.who.int/nutrition/publications/globaltargets2025_policybrief_overview/en/

WHO, 2018. Implementation Guidance: Protecting, Promoting and Supporting Breastfeeding in Facilities Providing Maternity and Newborn Services: The Revised Baby-Friendly Hospital Initiative. https://www.who.int/nutrition/publications/infantfeeding/bfhiimplementation/en/

WHO, 2020. Infant and young child feeding. World Health Organization. https://www.who.int/news-room/fact-sheets/detail/infant-and-young-child-feeding

Wilson AC, Forsyth JS, Greene SA, et al., 1998. Relation of infant diet to childhood health: seven-year follow up of cohort of children in Dundee Infant Feeding Study. BMJ, 316(7124):21-25. DOI: 10.1136/bmj.316.7124.21

World Breastfeeding Trends Initiative Steering Group, 2016. World Breastfeeding Trends Initiative: UK Report 2016. WBTi, London. https://ukbreastfeedingtrends.files.wordpress.com/2017/03/wbti-uk-report-2016-part-1-14-2$\underline{17 . p d f}$

Wright CM, Parkinson KN, and Drewett RF, 2004. Why are babies weaned early? Data from a prospective population based cohort study. Archives of Disease in Childhood, 89(9):813816. http://dx.doi.org/10.1136/adc.2003.038448 